\title{
Hélène Casanova-Robin, Diane et Actéon. Éclats et reflets d'un mythe à la Renaissance et à l'âge baroque
}

Dario Cecchetti

\section{(2) OpenEdition}

\section{Journals}

\section{Edizione digitale}

URL: https://journals.openedition.org/studifrancesi/39161

DOI: 10.4000/studifrancesi.39161

ISSN: 2421-5856

\section{Editore}

Rosenberg \& Sellier

\section{Edizione cartacea}

Data di pubblicazione: 1 décembre 2004

Paginazione: 352-353

ISSN: 0039-2944

\section{Notizia bibliografica digitale}

Dario Cecchetti, «Hélène Casanova-Robin, Diane et Actéon. Éclats et reflets d'un mythe à la Renaissance et à l'âge baroque», Studi Francesi [Online], 143 (XLVIII | II) | 2004, online dal 30 novembre 2015, consultato il 19 mai 2021. URL: http://journals.openedition.org/studifrancesi/39161 ; DOI: https:// doi.org/10.4000/studifrancesi.39161

Questo documento è stato generato automaticamente il 19 mai 2021

\section{(c) (i) $\odot$}

Studi Francesi è distribuita con Licenza Creative Commons Attribuzione - Non commerciale - Non opere derivate 4.0 Internazionale. 


\title{
Hélène Casanova-Robin, Diane et Actéon. Éclats et reflets d'un mythe à la Renaissance et à l'âge baroque
}

\author{
Dario Cecchetti
}

\section{NOTIZIA}

HÉLÈNE CASANOVA-ROBIN, Diane et Actéon. Éclats et reflets d'un mythe à la Renaissance et à l'âge baroque, Paris, Champion ("Études et Essais sur la Renaissance", XLVI), 2003, pp. 493.

1 Artemide-Diana è un personaggio mitologico tra i più ricorrenti nella letteratura $\mathrm{e}$ nell'arte del Rinascimento, carico di simbologie che acquistano valenze diverse di significato, con un oscillare dal polo positivo a quello negativo. Non si può propriamente parlare di un mito di Artemide-Diana che appartenga integralmente a questa divinità, ma di una serie di miti che riportano a una coppia umanodivina(Artemide ed Endimione, Artemide e Atteone, Artemide ed Ippolito, ecc.). Tra questi miti, un rilievo eccezionale, in area rinascimentale e barocca, assume quello di Artemide ed Atteone, al punto che Gisèle Mathieu-Castellani, in alcuni dei suoi lavori fondatori della riflessione sulla poesia barocca (Mythes de l'éros baroque, Paris, P.U.F., 1981, e Éros baroque. Anthologie thématique de la poésie amoureuse, Paris, Nizet, 1986), lo ha scelto in funzione emblematica, proprio per il suo alludere a uno dei temi più significativi dell'eros barocco, quello della beauté surprise. Ora di questo mito Hélène Casanova-Robin studia anzitutto la tradizione letteraria attraverso i secoli, a partire dagli archetipi antichi, che per l'A. si coagulano nelle Metamorfosi di Ovidio, per poi confrontare i modelli antichi con le resurgenze nella letteratura e nell'iconogragia del Cinquecento. Nella prima parte (Le mythe de Diane et Actéon à travers les siècles: la place prépondérante du poème d'Ovide dans sa transmission, pp. 21-175), dopo che si sono illustrate l'origine del mito e le più antiche testimonianze che ne abbiamo ricostruendo le occurrences littéraires e le occurrences iconographiques - e dopo che si è individuato nel topos del bagno (col disvelamento della nudità divina, non accessibile 
ad occhio umano) un motivo che trova ripetuta esemplificazione a livello di fabula ( $\mathrm{i}$ lavacri di Pallade e la cecità di Tiresia sono il corrispondente della storia di Atteone), vengono perlustrati i testi greci, in particolare ellenistici; ma è soprattutto al libro III delle Metamorfosi ovidiane che viene rivolta l'attenzione, per il fatto che qui prenderebbe forma definitiva la retractatio della storia di Diana e Atteone: la quale, "circondata da racconti che, nella maggior parte, riguardano la genealogia tebana, sembra iscriversi nella coerenza di un'opera fondatrice, in cui sono riportate di volta in volta le leggende e le altre 'parole' sulle origini del mondo" (p. 51). Sempre nell'epoca classica, vengono individuate alcune amplificationes della storia, in testi del periodo imperiale da Apuleio a Nonno. Inoltre, viene allestito e commentato un repertorio di occorrenze medievali, che trovano anch'esse il loro centro nell'Ovide moralisé: è nei testi medievali e umanistici che si afferma l'allegorizzazione del mito, non solo ma la fabula trova una sua realizzazione a livello di emblematica, come sarà poi ancora nel Rinascimento (in Alciato questa fabula raffigurerà uno dei vitia, la Perfidia). Nella seconda parte (La lecture ovidienne de la fable et ses échos dans la poésie et l'art figuré à la Renaissance et à l'âge baroque, pp. 179-392) si sottolinea come, nel proseguire il suo cammino secolare nel Rinascimento e nel Barocco, la fabula di Diana e Atteone conservi la sua virtualità simbolica. Certamente "il valore allegorico che le era stato conferito nel Medioevo apre largamente la strada all'utilizzazione simbolica che le sarà presto applicata nel discorso artistico e poetico. Effettivamente, l'immagine di Atteone rappresentante il Christus patiens o quella raffigurante il figliol prodigo o quella, diffusa ancora all'inizio del Cinquecento, dell'individuo tradito dal suo prossimo, scompaiono definitivamente. Di riscontro, il procedimento della 'lettura a chiave' si installa solidamente $e$, per questo intermediario, risorgono i mitemi ovidiani così come già Petrarca aveva saputo identificarli, per integrarli nella lirica d'amore" (p. 179). Inoltre il concetto stesso di metamorfosi si accorda con la nascita di un estetica del movimento, che gioca sull'instabilità degli esseri e delle forme, sulla visione di un mondo incerto, ove la coincidentia oppositorum è la caratteristica di una sensibilità ormai barocca.

2 Il lavoro di Hélène Casanova-Robin si raccomanda per l'ampia messe di testi citati (in appendice abbiamo anche un'interessante e utile antologia di testi antichi, medievali e cinquecenteschi, fino alle soglie del Barocco: pp. 405-451) e per la chiarezza e concretezza del discorso interpretativo. Ricca la bibliografia. 